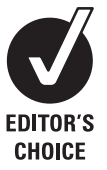

${ }^{1}$ Department of Maternal \& Child Health, UNC Gillings School of Global Public Health, Chapel Hill, North Carolina, USA; ${ }^{2}$ Duke University School of Medicine, Durham, North Carolina, USA:

${ }^{3}$ Cecil G Sheps Center for Health Services Research, University of North Carolina at Chapel Hill, Chapel Hill, North Carolina, USA

Correspondence to:

J G L Lee, Tobacco Prevention and Evaluation Program, Department of Family Medicine, UNC School of Medicine, CB\# 7595, 590 Manning Drive, Chapel Hill, North Carolina 27599 USA; jose.lee@unc.edu

Received 21 October 2008 Accepted 30 January 2009 Published Online First 10 February 2009

\title{
Tobacco use among sexual minorities in the USA, 1987 to May 2007: a systematic review
}

\author{
J G L Lee, ${ }^{1}$ G K Griffin, ${ }^{2}$ C L Melvin ${ }^{3}$
}

\section{ABSTRACT}

Objectives: This paper examines the prevalence of tobacco use among sexual minorities in the US through a systematic review of literature from 1987 to May 2007. Methods: Seven databases were searched for peerreviewed research (Cumulative Index to Nursing and Allied Health Literature (CINAHL), Cochrane Library via Wiley InterScience, Education Resources Information Center (ERIC), Health Source: Nursing/Academic, Institute for Scientific Information (ISI) Web of Science, PsycINFO via EBSCO Host and PubMed). No language restrictions were used. Abstracts were identified in the literature search $(n=734)$ and were independently read and coded for inclusion or exclusion by two reviewers. When agreement was not reached, a third reviewer acted as arbitrator. Abstracts were included if they presented data collected in the US from 1987 to May 2007 and reported prevalence or correlation of tobacco use with sexual minority status. Studies reporting data from HIV-positive samples were excluded. The identified articles $(n=46)$ were independently read by two reviewers who recorded key outcome measures, including prevalence and/or odds ratios of tobacco use, sample size and domain of sexuality (identity, behaviour, or desire). Factors relating to study design and methodology were used to assess study quality according to nine criteria.

Results: In the 42 included studies, 119 measures of tobacco prevalence or association were reported. The available evidence points to disparities in smoking among sexual minorities that are significantly higher than among the general population.

Conclusions: Ongoing, targeted interventions addressing smoking among sexual minorities are warranted in tobacco control programs.

Tobacco use is a major contributor to morbidity and mortality in the US and throughout the world. ${ }^{2}$ The relative burden of tobacco-related disease will be affected by disparities in tobacco use among different socio-demographic groups. In the US, disparities in smoking prevalence have been demonstrated by age, educational attainment, race/ethnicity and gender. ${ }^{3}$

With respect to sexual minority populations (including individuals with gay, lesbian, bisexual and transgender identity, and individuals with same-sex relationships and/or attraction), past research has suggested that sexual minority status is associated with higher risk of smoking. In 2001, Ryan and colleagues ${ }^{4}$ conducted the first systematic review of smoking among sexual minority populations and identified 12 studies reporting smoking prevalence by sexual orientation. Although the review found some evidence for higher smoking prevalence among sexual minorities, the strength of its conclusions was limited by poor sampling methodology in the identified articles as well as variations in definitions of sexual orientation and smoking. A more recent but limited review of smoking among sexual minority women identified 16 studies and came to similar conclusions. ${ }^{5}$

This article updates previous reviews and reports findings from 42 studies, many with rigorous sampling designs, identified through a systematic search of the published literature from 1987 to May 2007. The identified studies answer our key question: what is the prevalence of tobacco use in sexual minority populations compared to the general population? Our review includes information on gender, sampling methodology, and the domain of sexuality used to determine sexual minority status. Domain of sexuality has been shown to influence the measurement of smoking prevalence, ${ }^{6}$ and can be divided into at least three categories: identity (gay, lesbian, queer, bisexual, etc.), behaviour (same-sex relationships, sexual contacts, partners, etc.) and attraction (same-sex desire, which may or may not be acted upon). ${ }^{7}$ The findings of the present review are relevant to the primary care of sexual minority populations; the design, implementation and evaluation of effective tobacco control policy (to ensure disparities are addressed and not exacerbated); ${ }^{89}$ and, the improvement of research and data collection.

\section{METHODS}

\section{Data sources}

Seven databases were searched for peer-reviewed research articles (Cumulative Index to Nursing and Allied Health Literature (CINAHL), Cochrane Library via Wiley InterScience, Education Resources Information Center (ERIC), Health Source: Nursing/Academic, Institute for Scientific Information (ISI) Web of Science, PsycINFO via EBSCO Host and PubMed) published between 1987 and May 2007. No language or geographic restrictions were used. Search terms (see Appendix) covered sexual minority status and tobacco use. No attempts were made to identify unpublished or non-peer reviewed studies.

\section{Study selection}

A total of 734 abstracts were identified in the initial literature search. These were read and coded for inclusion or exclusion by two independent reviewers (GKG, JGLL). When agreement could not be reached, a third reviewer acted as arbitrator (CLM). Abstracts were included if they presented data collected in the US from 1987 to May 2007 and reported prevalence or correlation of tobacco use with sexual minority status. Like Ryan and 
colleagues, ${ }^{4}$ we excluded studies reporting data from HIVpositive samples because of potential confounding between HIV status and tobacco use. Abstracts that were either unavailable or not published in English were excluded. In cases where the abstract did not provide sufficient information for exclusion, studies were included until the full text of the article could be evaluated. Excluded articles that were otherwise relevant to tobacco use among sexual minorities were coded as background. In cases where the same data and study questions were reported upon in multiple publications, the most complete work was retained. Four articles including previously published data sets were thus excluded. ${ }^{10-13}$ Additionally, three articles ${ }^{14-16}$ whose results were incorporated into the one identified meta-analysis ${ }^{17}$ were excluded as we determined the meta-analysis to be more informative than the inclusion of several smaller samples. Lastly, studies that reported on the National Longitudinal Survey of Adolescent Health (known as Add Health) ${ }^{18-20}$ and the 1995 Massachusetts and Vermont Youth Risk Behaviour Surveillance Surveys ${ }^{21-23}$ were all included because they analysed the data for different study questions.

\section{Data extraction}

A total of 46 studies were found to meet all inclusion criteria and were retained for further analysis (fig 1). Full-text versions of these studies were obtained and read by two independent reviewers (GKG, JGLL), who recorded key outcome measures, including prevalence and/or odds ratios of tobacco use, sample size and domain of sexuality (identity, behaviour, or attraction). When agreement was not reached, a third reviewer acted as arbitrator (CLM). Because of the wide variety of study designs and study populations, we did not combine data.

\section{Quality of studies}

Study quality and design were assessed according to nine criteria: population-based (vs convenience) sampling, random sampling, equal risk at baseline between comparison groups, sampling not restricted to sexual minority populations, no stringent selection criteria (eg, having a family history of breast cancer or being the child of a nurse), bisexuality reported separately from exclusive homosexuality, similar ascertainment methods between comparison groups (using the same survey for the population of interest and the comparison group), statistical analysis for confounding variables (eg, age, education), and the ability to generalise the sample to the population of interest. Four studies meeting either none or just one of these criteria were classified as having a poor quality study design and were excluded from further analysis. ${ }^{2427}$ One exception was a study ${ }^{28}$ that was retained despite poor study quality because it reported on smoking prevalence by race and ethnicity among sexual minorities (for which there are very limited data). A total of 42 studies were retained for final analysis.

\section{RESULTS}

In all, 21 studies used population-based sampling, ${ }^{621-23} 29-45$ 6 were from large cohorts, ${ }^{18-20}{ }^{46-48} 1$ was a meta-analysis, ${ }^{17}$ and the remaining 12 were convenience samples. ${ }^{28}{ }^{49-59}$ Results of the two previous reviews are not reported here. ${ }^{45}$

Studies defined tobacco use in nine different ways or failed to report a definition. In most studies, tobacco use was defined as smoking in the past month, current smoking, or smoking in the past month with over 100 cigarettes consumed over the course of the respondent's lifetime (table 1).

The 42 included studies reported 119 measures of tobacco prevalence or association. Most measures reported the prevalence of smoking or smokeless tobacco use among a sexual minority population $(n=97)$. Of these, 88 reported prevalence in a comparison population. Some $(\mathrm{n}=59)$ reported an odds ratio (OR) or risk ratio (RR), but only 37 reported the corresponding 95\% confidence intervals (CIs). Very few $(n=12)$ reported other measures of association. One reported only non-significance. A total of 43 measures were reported for men, 67 for women and 9 (reported in the Appendix) aggregated gender. Two reported on smokeless tobacco use and the
Figure 1 Summary of literature search and study identification.

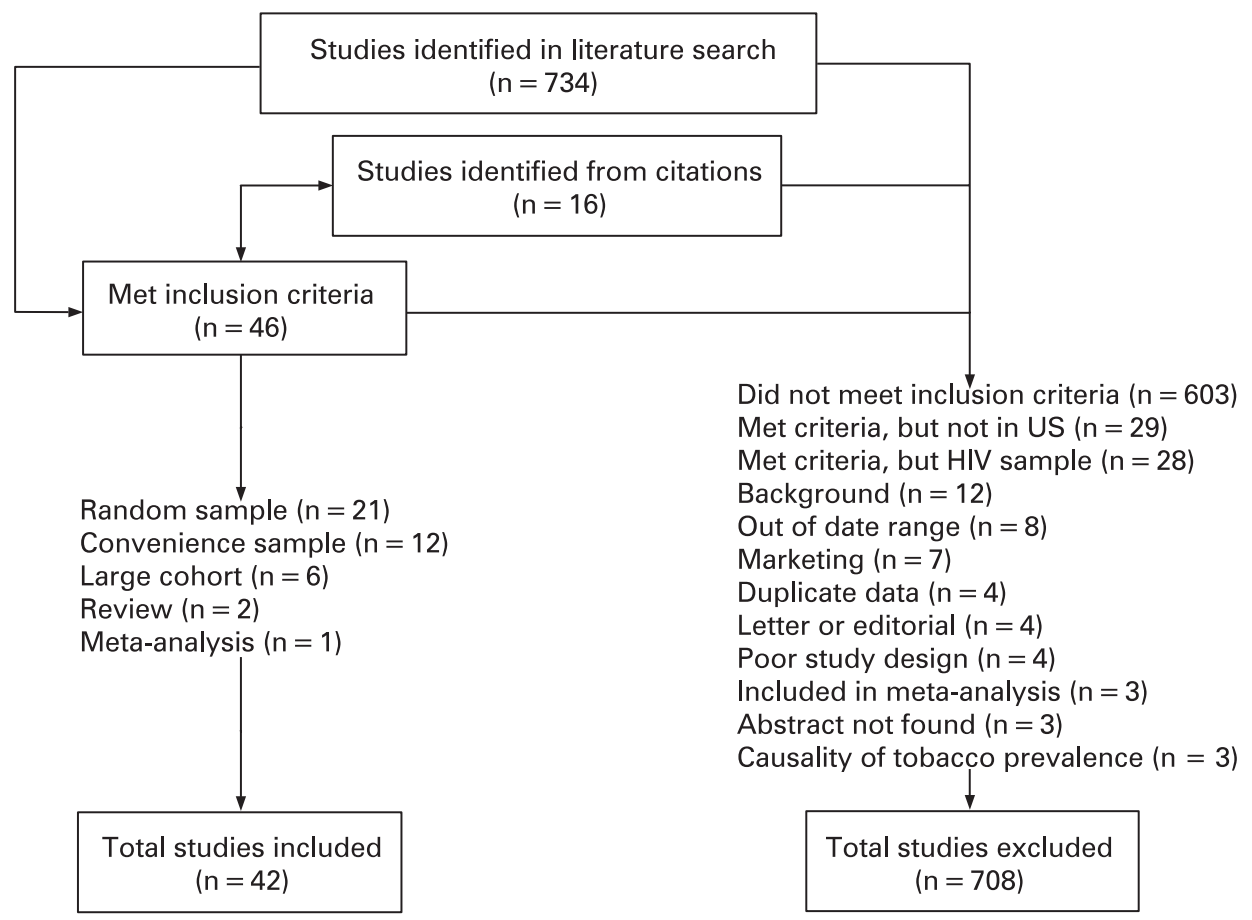


Table 1 Definitions of tobacco use identified

\begin{tabular}{lc}
\hline Definition & $\begin{array}{l}\text { No. of measures of } \\
\text { association or estimates of } \\
\text { prevalence }\end{array}$ \\
\hline Month* & 51 \\
Current & 31 \\
Month +100 & 12 \\
Number of days of smoking/use in last month* & 10 \\
"Have you ever smoked cigarettes regularly, that is, & 5 \\
at least one cigarette every day for 30 days?" & 2 \\
More than half a pack per day & 2 \\
Used cigarettes more than six times in lifetime & 3 \\
Year & 1 \\
Use two or more times daily & 2 \\
Unknown & 119 \\
Total & \\
\hline
\end{tabular}

*Includes a measure of smokeless tobacco use.

remainder reported on cigarette smoking. Table 2 illustrates the number of measures for men and women by domain of sexuality.

Among studies reporting ORs and 95\% CIs, ORs for sexual minority tobacco use ranged from 0.9 to 6.3 in comparison to heterosexual populations. Figure 2 graphs the ORs that were reported with $95 \%$ confidence intervals by gender, stratifying by homosexuality, bisexuality and the aggregation thereof. Each category may include multiple domains of sexuality: behaviour, attraction and/or identity. Studies generally showed a positive association between sexual minority status and cigarette use with ORs between 1.5 and 2.5.

\section{Smoking among sexual minority women}

The 2006 National Health Interview Survey reported the national estimate of smoking among women in the US to be $18 \% .^{3}$ For women who reported exclusively homosexual identity, behaviour, or attraction, ORs ranged from 0.6 (exclusively same-sex behaviour) to 4.9 (exclusively lesbian identity) (table 3 (online only)) both in a single random sample of college students at one Midwestern university. ${ }^{6}$ All other ORs, however, fell between 1.2 and 2.0. Prevalence of smoking, which is complicated by the use of different definitions of smoking, was lowest ( $7 \%$ to $10 \%$ ) among women participating in biomedical studies, among older women, and in a California convenience sample. Among adolescents, there was no statistically significant difference in smoking prevalence reported in two studies using data from Add Health. ${ }^{18} 19$ The prevalence in the four randomly sampled, non-college studies ranged from

Table 2 Definitions of sexual minority status

\begin{tabular}{lll}
\hline Gender & Definition & $\begin{array}{l}\text { No. of measures of association or } \\
\text { estimates of prevalence }\end{array}$ \\
\hline Women & Identity & 38 \\
& Behaviour & 18 \\
& Attraction & 6 \\
Aggregated & 5 \\
\multirow{3}{*}{ Men } & Identity & 20 \\
& Behaviour* & 15 \\
& Attraction & 6 \\
Men and Women & Aggregated & 2 \\
\end{tabular}

*Includes a measure of smokeless tobacco use; †see Appendix.
$25 \%$ to $37 \%$. All randomly sampled, non-college studies were from California.

Among women with bisexual identity, behaviour, or attraction, ORs ranged from 1.5 among women reporting past female partners but a current male partner in the California Women's Health Survey ${ }^{30}$ to 3.5 in the National Alcohol Survey ${ }^{33}$ (table 3 (online only)). There was a notable and statistically significant risk for adolescent women in Add Health and Growing Up Today (a cohort of children of nurses enrolled in the Nurses' Health Study II) that was not seen for adolescent women reporting exclusive homosexuality in Add Health (exclusive homosexuality was not analysed in Growing Up Today). ${ }^{18} 1946$ In the five randomly sampled non-college studies, prevalence ranged from $27 \%$ to $50 \%$. All but one were from California.

When bisexual and homosexual identity, behaviour and attraction are aggregated, the risk of smoking was also elevated. Most alarmingly, the odds of smoking among lesbian and bisexual adolescents in Growing Up Today, were 6.3 (95\% CI 3.4 to 11.6$)$ times greater than for their straight counterparts. ${ }^{46}$ Only one study was randomly sampled outside of a university campus: the California Women's Health Survey reported a 1.8 OR (95\% CI 1.5 to 2.3 ) of current smoking for any women with one or more same-sex partner compared to women with only opposite-sex partners. ${ }^{30}$

Among studies reporting on the association of smoking with female sexual minorities, all random samples outside of college students were conducted in California, except for a small sample from the National Alcohol Survey. With the exception of women in California reporting "other race", when compared to a Latina reference group, all randomly sampled, non-collegebased studies that reported an OR and CI showed a statistically significant association between female sexual minority status and cigarette smoking, ranging from 1.5 to 3.5. Of these, all ORs but one fell between 1.5 and 2.1 .

\section{Smoking among sexual minority men}

The 2006 National Health Interview Survey reported the national estimate of smoking among men in the US to be $24 \% .^{3}$ For men who reported exclusively homosexual identity, behaviour, or attraction, ORs ranged from 1.1 in a national random sample of college students ${ }^{34}$ to 2.4 in a random sample of a northern California healthcare plan ${ }^{37}$ (table 4 (online only)). Only two studies were randomly sampled outside of college campuses. The previously mentioned California healthcare plan and the California Health Interview Survey ${ }^{45}$ both found the odds of smoking to be over twice as great as for heterosexual men (significant at OR 2.4 and 2.1, respectively). As among sexual minority adolescent women, exclusive homosexuality was generally associated with decreased likelihood of smoking in Add Health. ${ }^{19} 19$ The prevalence in randomly sampled, noncollege studies ranged from $24 \%$ to $33 \%$.

Among men with bisexual identity, behaviour, or attraction, ORs ranged from 0.9 for bisexual men in the California Health Interview Survey ${ }^{45}$ to 2.6 for "mostly heterosexual" men in a random sample at a Midwestern university. ${ }^{6}$ As with sexual minority adolescent women, bisexuality was generally associated with increased risk of cigarette smoking in Add Health and Growing Up Today for men. ${ }^{18} 1946$

When bisexual and homosexual identity, behaviour and attraction were aggregated, one large random sample in Tucson, Arizona and Portland, Oregon, found an elevated prevalence of smoking among white gay or bisexual men (42\% vs $29 \%$ for heterosexual men) but not among American Indian/ Native American men and Asian/Pacific Islander men. ${ }^{44}$ Youth 
Figure 2 Odds ratios and 95\% confidence intervals (Cls) of cigarette smoking among sexual minority men and women.

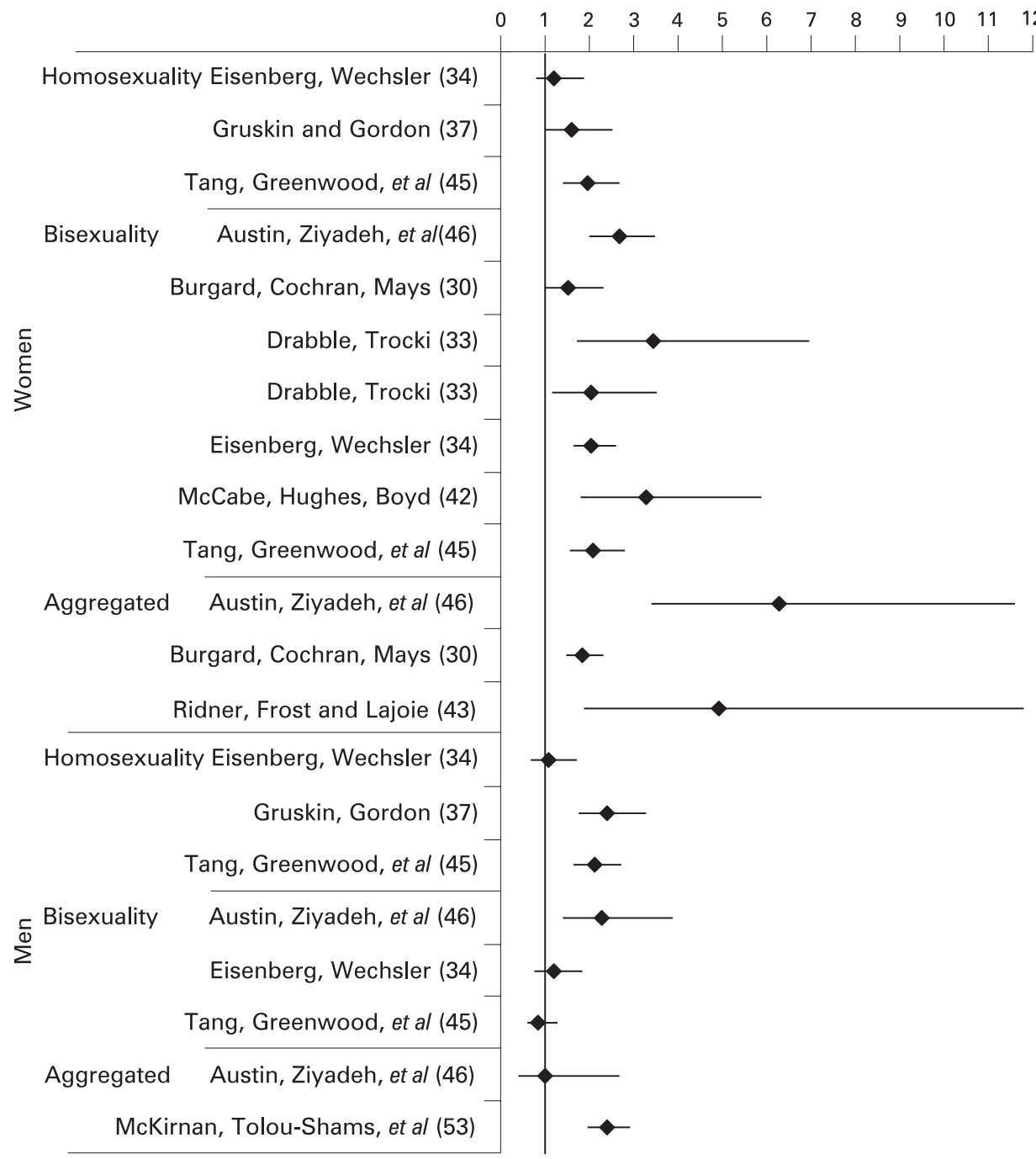

Risk Behaviour Surveillance Surveys in Massachusetts and Vermont found elevated risk for sexual minority male students. ${ }^{22} 23$

As with studies of female sexual minorities, most randomly sampled studies were conducted on college campuses or in California. The two randomly sampled, non-college studies including ORs reported significant results (OR 2.195\% CI 1.7 to 2.7 and OR 2.4 95\% CI 1.8 to 3.3) for smoking among gay men. ${ }^{37} 45$ The data for bisexual men are equivocal with nonsignificant findings in all samples except for adolescent men with bisexual behaviour, attraction and/or identity who were at elevated risk. ${ }^{18} 1946$

\section{Studies on sexual minority identity and race/ethnicity}

When stratified by race and ethnicity, three studies reported on sexual minority men ${ }^{4044}$ and four on sexual minority women. ${ }^{28} 40458$ One additional study reports on measures combining men and women and is reported in the Appendix. ${ }^{20}$ Only Stall and colleagues sampled randomly, using a random sample from Tucson, Arizona and Portland, Oregon phone books. Black gay or bisexual men had almost double the smoking prevalence of heterosexual black men (62\% vs 34\%). Hispanic, Asian and American Indian men had relatively similar smoking prevalence to heterosexual counterparts. ${ }^{44}$

\section{Families, caregivers and couples}

In 7 years of data from the National Health Interview Survey, Heck and Jacobson reported that 29\% of women and $31 \%$ of men in a same-sex partnered household currently smoke compared to $19 \%$ and $23 \%$ of women and men, respectively, in opposite-sex partnered households. ${ }^{39}$ The National Health Interview Survey provides the best national data available, albeit including only partnered individuals.

Little is known about smoking in gay and lesbian families. Sanchez and colleagues reported on the percentage of Hispanic (78\%) and African-American (58\%) lesbian or bisexual smokers who care for their own children or the children of a partner in a largely dance-club-based convenience sample in the Bronx, New York. ${ }^{58}$ We identified no other studies reporting on smoking and sexual minority families, parents, or caregivers.

\section{DISCUSSION}

This review provides strong evidence for the existence of an elevated prevalence of smoking among sexual minorities with odds ratios between 1.5 and 2.5 when comparing against heterosexual counterparts. Among sexual minority women, odds ratios were between 1.5 and 2.0 when comparing against heterosexual women. Among sexual minority men, odds ratios are generally between 2.0 and 2.5 when comparing against 
heterosexual men. Evidence for adult bisexual men, however, was inconclusive. Limited evidence suggests that bisexual adolescents are at higher risk than their exclusively homosexual peers. A rigorously sampled study in California, which fell outside of our date range, confirms these findings and suggests that prevalence among sexual minority women may be even higher than our estimates. ${ }^{60}$

The aetiology of these tobacco use disparities can be understood within the social/ecological model articulated by Bronfenbrenner, ${ }^{61}$ wherein differences in health status are based in the dominant social, economic and political environment and generated at multiple levels: interpersonal, family, community and society. With respect to sexual minority populations, sexual orientation is thus conceptualised not as the cause of tobacco disparities but as a marker of health risk caused by interactions with the social/ecological environment. Using the Bronfenbrenner model, we can begin to conceptualise how sexual minority status could be a marker of tobacco initiation risk and also have a protective effect-depending on the particular interaction between identity, development, ${ }^{62}$ and the socio-political environment.

Analyses of Add Health data found greatly reduced risk for adolescents who had only same-sex relationships versus those adolescents with same-sex and opposite-sex relationships. ${ }^{18} 19$ Add Health data could reflect adolescent experiences with difficult stages of identity development or extra stress associated with bisexual identity, but no measures of either were reported. Adolescents identifying as "mostly heterosexual" in Growing Up Today study were also at significantly higher risk of smoking than their "fully" heterosexual peers, but Growing Up Today analyses aggregated bisexual and gay identity, ${ }^{46}$ and thus cannot confirm the Add Health finding. Many models of identity development for sexual minorities exist, but few have been rigorously tested across sexual minority populations. ${ }^{63} \mathrm{We}$ identified no studies that reported tobacco use by stage of identity development. Because of the aggregation of bisexual behaviour, identity and attraction in all other studies that focus on adolescents, the Add Health finding cannot be verified. The same protection found in Add Health is also evident in some studies of college-age adolescents, ${ }^{64}$ but is not evident among adults. (That exclusively same-sex relationships are protective should not be misconstrued to label bisexuality a risk factor. The aggregation of bisexuality and different stages of identity development could be a driving force in this finding.) It is possible that adolescents age out of the protective effects of sexual minority identity as social and physical environments change. Further research should emphasise the importance of resiliency, protective effects of identity and "within-group" differences in risk. ${ }^{62}$

Efforts to address disparities in smoking require a better understanding of the aetiology of smoking among sexual minorities. Although a thorough discussion of this subject is outside the scope of this paper, several articles identified suggested possible causal pathways for the creation of tobacco disparities among sexual minorities. ${ }^{64-67}$ Identified pathways included the linkage between gay and lesbian social spaces (such as bars) with smoking, ${ }^{68}$ initiation of smoking due to violence, stress and discrimination, ${ }^{69}$ as well as barriers to healthcare access and treatment services. Targeted marketing by the tobacco industry, which has gone so far as to link "smokers' rights" with rights for marriage equality, ${ }^{70}$ is also a likely contributing factor. ${ }^{71-76}$ Further research into these areas is justified to guide the development of effective interventions.

\section{Race and ethnicity}

Addressing disparities also requires a better understanding of the impact of race and ethnicity on tobacco use among sexual minorities. Race and ethnicity, like sexual minority status, do not have an intrinsic link to tobacco, substance abuse, or other risk behaviours. ${ }^{77}$ However, disparities in smoking among racial and ethnic groups within the US do exist, ${ }^{3}$ and there is reason to believe that they are determined by the different social, economic, environmental and political contexts of racial and ethnic minorities. How, when and for whom race, ethnicity and sexual minority status combine detrimentally and/or protectively remains a question. ${ }^{78} 79$

\section{Limitations}

Some variability in smoking prevalence was seen across the 42 identified studies. In convenience samples taken at bars and clubs, over-estimates of prevalence are likely given the selection bias inherent in bar samples. As this review relied solely upon studies in the published literature, there is the potential for bias against unpublished studies that showed a null result. Additionally, although some studies stratified results by age, the present review only included the aggregated measure across all ages. Tobacco use among young people, in particular, may appear attenuated given the evidence that young people are more likely to smoke than adults. ${ }^{3}$ While the findings of this review could offer some insight into tobacco use among sexual minorities throughout the world, further research is warranted to determine its relevance to contexts outside of the US, particularly as the tobacco industry shifts its focus to lowincome countries in the "Global South".

As noted in previous systematic reviews of smoking, ${ }^{80}$ a major limitation was the lack of standardised definitions of smoking. Smoking was defined in ways as different as having smoked more than six cigarettes during one's lifetime ${ }^{57}$ and more than two cigarettes per day. ${ }^{51}$ The operationalisation of sexual minority status also frustrates attempts to compare across studies. Previous research has documented widespread inconsistencies in how researchers conceptualise and use sexual orientation. ${ }^{81-83}$ First, measurement of sexual minority status by different domains of sexuality complicates comparisons. Second, research conducted within one domain of sexuality (eg, attraction) may not be applicable for programs targeted by another domain (eg, identity). Third, our understanding of causal pathways for tobacco initiation may be affected by how sexual orientation is defined.

When reporting on tobacco use by race and/or ethnicity, some studies used a comparison group of heterosexual men or women from the same racial/ethnic group, while others compared racial and ethnic groups within the sexual minority sample using either Latino $^{45}$ or white ${ }^{20}$ populations for comparison.

Six significant gaps in the published research were identified. First, there were no data on smoking among transgender

\section{What this paper adds}

- There is compelling evidence that an elevated prevalence of tobacco use among lesbian, gay and bisexual men and women exists.

- National and state surveillance systems should incorporate sexual minority status to monitor the elevated use of tobacco by gays and lesbians. 
populations. Second, there were no evaluations of smoking prevention or cessation interventions in sexual minority populations. Third, data on race and ethnicity remains sparse, particularly from population-based samples. Fourth, there is only one study on adolescent tobacco use that does not aggregate bisexuality. Fifth, only two measures of smokeless tobacco use were identified, although a recent study outside the date range of our search reports a lower prevalence of smokeless tobacco use among sexual minorities in California. ${ }^{84}$ Sixth, there is little to no evidence about the prevalence of tobacco use among sexual minority families, particularly families with children.

This last gap is of increasing importance as more sexual minority couples start families and parent children, and as legal protections with respect to marriage rights and civil unions evolve. ${ }^{85}$ Preconceptional health for lesbians may not be considered a high priority by health care professionals, ${ }^{86}$ and it could be beneficial to begin emphasising tobacco prevention and cessation as lesbians start families and initiate pregnancy. In this regard, future research could investigate smoking prevalence among pregnant sexual minority women, among partnered sexual minority men and women, or among those parenting or planning to parent children.

\section{Conclusions}

Increased attention to smoking among sexual minority populations is warranted in clinical practice and in the creation of prevention and treatment programs. In examining the ample evidence of disparities in suicidal ideation among sexual minority adolescents, Morrison and L'Heureux noted that the "[p]revention of GLBO [gay, lesbian, bisexual, and queer] adolescent suicide thus could entail treating the environments that interface with GLBO youth in addition to treating the adolescents themselves". ${ }^{87}$ The same may well be true for elevated prevalence of smoking among sexual minorities. Moreover, there are specific evidence-based steps that can be taken to reduce the impact of smoking on sexual minority communities.

Prevalence could be assessed and monitored through Youth Risk Behaviour Surveillance Surveys, Youth Tobacco Surveys, Behavioural Risk Factor Surveillance Surveys and Adult Tobacco Surveys. Many states, however, do not include sexual orientation, thus hindering monitoring efforts despite the fact that sampling methodology has been crucial in researchers' understanding of gay and lesbian health and well-being. ${ }^{88}$ Population-based interventions such as increasing taxes on tobacco products and banning advertising should be combined with approaches that seek to reduce disparities in vulnerable populations. ${ }^{9}$ These might include social marketing efforts, mass media campaigns in the gay and lesbian press, community recognition of tobacco as a problem, ${ }^{89} 90$ extra efforts for smoke-free gay and lesbian venues, targeted cessation services, ${ }^{91}$ community rejection of tobacco industry sponsorship of events and ongoing collaboration with the National LGBT Tobacco Control Network (http://www.lgbttobacco.org/). Given the leitmotiv of smoking as a health inequality in sexual minorities' lives, local, state and federal tobacco programs should target lesbian, gay, bisexual, transgender (LGBT) populations in tobacco prevention and cessation interventions and include priority population indicators in the evaluation of program outcomes.

\section{APPENDIX}

Table A1 Measures of tobacco use among gender-aggregated samples

\begin{tabular}{|c|c|c|c|c|c|c|c|}
\hline Study & Odds ratio $(95 \%$ Cl) & Prevalence & Comparison & $\mathbf{n}$ & Population & Sampling frame & $\begin{array}{l}\text { Definition of } \\
\text { tobacco use }\end{array}$ \\
\hline $\begin{array}{l}\text { Faulkner and } \\
\text { Cranston }^{35}\end{array}$ & - & 38.2 & 41.5 & 105 & $\begin{array}{l}\text { Students reporting sexual contact with the } \\
\text { same sex }\end{array}$ & $\begin{array}{l}\text { Massachusetts, sampled } \\
\text { with a random (YRBS) } \\
\text { sample during } 1993\end{array}$ & Month \\
\hline Garofalo et $a l^{21}$ & 1.38 (1.2 to 1.59$)$ & 33.7 & 7.7 & 104 & $\begin{array}{l}\text { Gay adolescents, lesbian adolescents, or } \\
\text { bisexual adolescents }\end{array}$ & $\begin{array}{l}\text { Massachusetts, sampled } \\
\text { with a random (YRBS) } \\
\text { sample during } 1995\end{array}$ & $\begin{array}{l}\text { Month, smokeless } \\
\text { tobacco use }\end{array}$ \\
\hline Garofalo et $a l^{21}$ & - & 59.3 & 35.2 & 104 & $\begin{array}{l}\text { Gay adolescents, lesbian adolescents, or } \\
\text { bisexual adolescents }\end{array}$ & $\begin{array}{l}\text { Massachusetts, sampled } \\
\text { with a random (YRBS) } \\
\text { sample during } 1995\end{array}$ & $\begin{array}{l}\text { One or more } \\
\text { cigarettes per day } \\
\text { for the past } \\
30 \text { days }\end{array}$ \\
\hline \multirow[t]{2}{*}{ Rostosky et a ${ }^{20}$} & 0.47 (0.26 to 0.83 ) & - & - & 68 & $\begin{array}{l}\text { African-American adolescent men and } \\
\text { women reporting no same-sex attraction at } \\
\text { Add Health Wave I and reporting GLB } \\
\text { identity at Wave III (comparison is white } \\
\text { adolescent men and women reporting same- } \\
\text { sex attraction at Wave I and GLB identity at } \\
\text { Wave III) }\end{array}$ & $\begin{array}{l}\text { USA, Add Health cohort } \\
\text { study during } 2001\end{array}$ & Month \\
\hline & $0.4(0.21$ to 0.78$)$ & - & - & 52 & $\begin{array}{l}\text { "Other race" adolescent men and women } \\
\text { reporting no same-sex attraction at Add } \\
\text { Health Wave I and reporting GLB identity at } \\
\text { Wave III }(n=52) \text { (comparison is white } \\
\text { adolescent men and women reporting no } \\
\text { same-sex attraction at Wave I and reporting } \\
\text { GLB identity at Wave III) }\end{array}$ & & \\
\hline
\end{tabular}


Table A1 Continued

\begin{tabular}{|c|c|c|c|c|c|c|c|}
\hline Study & Odds ratio $(95 \% \mathrm{Cl})$ & Prevalence & Comparison & $\mathbf{n}$ & Population & Sampling frame & $\begin{array}{l}\text { Definition of } \\
\text { tobacco use }\end{array}$ \\
\hline & 0.82 (0.36 to 1.88$)$ & 40 & 33 & 113 & $\begin{array}{l}\text { Adolescent men and women reporting same- } \\
\text { sex attraction at Add Health Wave I and GLB } \\
\text { identity at Wave III }\end{array}$ & & \\
\hline
\end{tabular}

GLB, gay, lesbian, bisexual; YRBS, Youth Risk Behavior Survey.

Acknowledgements: Special thanks to Mellanye Lackey and the UNC Health Sciences Library family for excellent support throughout the research process and to Anna Freeman, Anna McCullough and our very helpful reviewers for constructive feedback on the text.

Funding: This work was partially supported by The Robert Wood Johnson Foundation's Smoke-Free Families National Dissemination Office (grant no. 053311). The findings and conclusions in this manuscript are those of the authors and do not necessarily represent the views of the Robert Wood Johnson Foundation.

Competing interests: None.

\section{REFERENCES}

1. Centers for Disease Control and Prevention (CDC). Smoking-attributable mortality, years of potential life lost, and productivity losses-United States, 20002004. MMWR Morb Mortal Wkly Rep 2008;57:1226-8.

2. World Health Organization. WHO Report on the Global Tobacco Epidemic 2008: The MPOWER Package. New York, USA: World Health Organization, 2008.

3. Centers for Disease Control and Prevention (CDC). Cigarette smoking among adults_-United States, 2006. MMWR Morb Mortal Wkly Rep 2007:56:1157-61.

4. Ryan H, Wortley PM, Easton A, et al. Smoking among lesbians, gays, and bisexuals: a review of the literature. Am J Prev Med 2001:21:142-9.

5. Hughes TL, Jacobson KM. Sexual orientation and women's smoking. Curr Womens Health Rep 2003;3:254-61.

6. McCabe SE, Hughes TL, Bostwick W, et al. Assessment of difference in dimensions of sexual orientation: implications for substance use research in a college-age population. J Stud Alcohol 2005;66:620-9.

7. Laumann E0, Gagnon JH, Michael RT, et al. Homosexuality. In: The social organization of sexuality: sexual practices in the United States. Chicago, Illinois, USA: University of Chicago Press, 1994: 283-320.

8. Centers for Disease Control and Prevention (CDC). Best practices for comprehensive tobacco control programs. Atlanta, Georgia, USA: US Department of Health and Human Services, Centers for Disease Control and Prevention, National Center for Chronic Disease Prevention and Health Promotion, Office on Smoking and Health, 2007.

9. Frohlich $\mathbf{K L}$, Potvin L. Transcending the known in public health practice: the inequality paradox: the population approach and vulnerable populations. Am J Public Health 2008;98:216-21.

10. Dibble SL, Roberts SA, Robertson PA, et al. Risk factors for ovarian cancer: lesbian and heterosexual women. Oncol Nurs Forum 2002;29:E1-7.

11. Grindel CG, McGehee LA, Patsdaughter CA, et al. Cancer prevention and screening behaviors in lesbians. Women Health 2007:44:15-39.

12. Rosario M, Schrimshaw EW, Hunter J. Predictors of substance use over time among gay, lesbian, and bisexual youths: an examination of three hypotheses. Addict Behav 2004:29:1623-31.

13. Skinner WF. The prevalence and demographic predictors of illicit and licit drug use among lesbians and gay men. Am J Public Health 1994:84:1307-10.

14. White JC, Dull VT. Health risk factors and health-seeking behavior in lesbians. $J$ Womens Health 1997;6:103-12.

15. Roberts SJ, Sorensen L. Health related behaviors and cancer screening of lesbians: results from the Boston Lesbian Health. Women Health 1999;28:1.

16. Rankow EJ, Tessaro I. Cervical cancer risk and Papanicolaou screening in a sample of lesbian and bisexual women. J Fam Pract 1998:47:139-43.

17. Cochran SD, Mays VM, Bowen D, et al. Cancer-related risk indicators and preventive screening behaviors among lesbians and bisexual women. Am J Public Health 2001;91:591-7.

18. Udry JR, Chantala K. Risk assessment of adolescents with same-sex relationships. J Adolesc Health 2002;31:84-92.
19. Russell ST, Driscoll AK, Truong N. Adolescent same-sex romantic attractions and relationships: implications for substance use and abuse. Am J Public Health 2002;92:198-202.

20. Rostosky SS, Danner F, Riggle ED. Is religiosity a protective factor against substance use in young adulthood? Only if you're straight! J Adolesc Health 2007;40:440-7.

21. Garofalo R, Wolf RC, Kessel S, et al. The association between health risk behaviors and sexual orientation among a school-based sample of adolescents. Pediatrics 1998;101:895-902.

22. DuRant RH, Krowchuk DP, Sinal SH. Victimization, use of violence, and drug use at school among male adolescents who engage in same-sex sexual behavior. J Pediatr 1998; 133:113-18.

23. Bontempo DE, D'Augelli AR. Effects of at-school victimization and sexual orientation on lesbian, gay, or bisexual youths' health risk behavior. J Adolesc Health 2002:30:364-74.

24. Amadio DM, Chung YB. Internalized homophobia and substance use among lesbian, gay, and bisexual persons. J Gay Lesbian Soc Serv Issues Pract Policy Res 2004:17(1):83-101.

25. Marrazzo JM, Koutsky LA, Stine KL, et al. Genital human papillomavirus infection in women who have sex with women. J Infect Dis 1998:178:1604-9.

26. Roberts SJ, Patsdaughter CA, Grindel CG, et al. Health related behaviors and cance screening of lesbians: results of the Boston Lesbian Health Project II. Women Health 2004;39:41-55.

27. Nieto DS. Who is the male homosexual? A computer-mediated exploratory study of gay male bulletin board system (BBS) users in New York City. J Homosexuality 1996;30:97-124.

28. Mays VM, Yancey AK, Cochran SD, et al. Heterogeneity of health disparities among African American, Hispanic, and Asian American women: unrecognized influences of sexual orientation. Am J Public Health 2002;92:632-9.

29. Bowen DJ, Bradford JB, Powers D, et al. Comparing women of differing sexua orientations using population-based sampling. Women Health 2004:40:19-34.

30. Burgard SA, Cochran SD, Mays VM. Alcohol and tobacco use patterns among heterosexually and homosexually experienced California women. Drug Alcohol Depend 2005;77:61-70.

31. Diamant AL, Wold C. Sexual orientation and variation in physical and mental health status among women. J Womens Health (Larchmt) 2003;12:41-9.

32. Diamant AL, Wold C, Spritzer K, et al. Health behaviors, health status, and access to and use of health care: a population-based study of lesbian, bisexual, and heterosexual women. Arch Fam Med 2000:9:1043-51.

33. Drabble L, Trocki K. Alcohol consumption, alcohol-related problems, and other substance use among lesbian and bisexual Women. J Lesbian Studies 2005;9:19-30.

34. Eisenberg $\mathbf{M}$, Wechsler $H$. Substance use behaviors among college students with same-sex and opposite-sex experience: results from a national study. Addict Behav 2003:28:899-913.

35. Faulkner $\mathbf{A H}$, Cranston K. Correlates of same-sex sexual behavior in a random sample of Massachusetts high school students. Am J Public Health 1998;88:262-6.

36. Greenwood GL, Paul JP, Pollack LM, et al. Tobacco use and cessation among a household-based sample of US urban men who have sex with men. Am J Public Health 2005;95:145-51.

37. Gruskin EP, Gordon N. Gay/lesbian sexual orientation increases risk for cigarette smoking and heavy drinking among members of a large Northern California health plan. BMC Public Health 2006;6:241.

38. Gruskin EP, Hart S, Gordon N, et al. Patterns of cigarette smoking and alcohol use among lesbians and bisexual women enrolled in a large health maintenance organization. Am J Public Health 2001;91:976-9.

39. Heck JE, Jacobson JS. Asthma diagnosis among individuals in same-sex relationships. J Asthma 2006:43:579-84.

40. Krieger N, Sidney S. Prevalence and health implications of anti-gay discrimination: a study of black and white women and men in the CARDIA cohort. Coronary Artery Risk Development in Young Adults. Int J Health Serv 1997;27:157-76. 
41. McCabe SE, Boyd C, Hughes TL, et al. Sexual identity and substance use among undergraduate students. Subst Abus 2003;24:77-91.

42. McCabe SE, Hughes TL, Boyd CJ. Substance use and misuse: are bisexual women at greater risk? J Psychoactive Drugs 2004:36:217-25

43. Ridner SL, Frost K, Lajoie AS. Health information and risk behaviors among lesbian, gay, and bisexual college students. J Am Acad Nurse Pract 2006;18:374-8.

44. Stall RD, Greenwood GL, Acree $\mathrm{M}$, et al. Cigarette smoking among gay and bisexual men. Am J Public Health 1999;89:1875-8.

45. Tang H, Greenwood GL, Cowling DW, et al. Cigarette smoking among lesbians, gays, and bisexuals: how serious a problem? (United States). Cancer Causes Control 2004; 15:797-803.

46. Austin SB, Ziyadeh N, Fisher LB, et al. Sexual orientation and tobacco use in a cohort study of US adolescent girls and boys. Arch Pediatr Adolesc Med 2004; 158:317-22.

47. Case $\mathbf{P}$, Austin SB, Hunter DJ, et al. Sexual orientation, health risk factors, and physical functioning in the Nurses' Health Study II. J Womens Health (Larchmt) 2004; 13:1033-47.

48. Valanis BG, Bowen DJ, Bassford T, et al. Sexual orientation and health: comparisons in the women's health initiative sample. Arch Fam Med 2000;9:843-53.

49. Aaron DJ, Markovic N, Danielson ME, et al. Behavioral risk factors for disease and preventive health practices among lesbians. Am J Public Health 2001;91:972-5.

50. Burleson MH, Trevathan WR, Gregory WL. Sexual behavior in lesbian and heterosexual women: relations with menstrual cycle phase and partner availability. Psychoneuroendocrinology 2002;27:489-503.

51. Diamant AL, Schuster MA, Lever J. Receipt of preventive health care services by lesbians. Am J Prev Med 2000:19:141-8.

52. Koh AS. Use of preventive health behaviors by lesbian, bisexual, and heterosexual women: questionnaire survey. West J Med 2000;172:379-84

53. McKirnan DJ, Tolou-Shams M, Turner L, et al. Elevated risk for tobacco use among men who have sex with men is mediated by demographic and psychosocial variables. Subst Use Misuse 2006;41:1197-208.

54. Powers D, Bowen DJ, White J. The influence of sexual orientation on health behaviors in women. J Prevention Intervention Comm 2001;22:43-60.

55. Roberts SA, Dibble SL, Nussey B, et al. Cardiovascular disease risk in lesbian women. Womens Health Issues 2003;13:167-74.

56. Roberts SA, Dibble SL, Scanlon JL, et al. Differences in risk factors for breast cancer: lesbian and hterosexual women. J Gay Lesbian Med Assn 1998;2:93-101.

57. Rosario M, Hunter J, Gwadz M. Exploration of substance use among lesbian, gay, and bisexual youth: prevalence and correlates. J Adolesc Res 1997;12:454-76.

58. Sanchez JP, Meacher P, Beil R. Cigarette smoking and lesbian and bisexual women in the Bronx. J Community Health 2005;30:23-37.

59. Skinner WF, Otis MD. Drug and alcohol use among lesbian and gay people in a southern U.S. sample: epidemiological, comparative, and methodological findings from the Trilogy Project. J Homosex 1996;30:59-92.

60. Gruskin EP, Greenwood GL, Matevia M, et al. Disparities in smoking between the lesbian, gay, and bisexual population and the general population in California. Am J Public Health 2007;97:1496-502

61. Bronfenbrenner U. The ecology of human development: experiments by nature and design. Cambridge, Massachusetts, USA: Harvard University Press, 1979.

62. Savin-Williams RC. A critique of research on sexual-minority youths. J Adolesc 2001;24:5-13.

63. Eliason MJ, Schope R. Shifting sands or solid foundation? Lesbian, gay, bisexual, and transgender identity formation. In: Meyer IH, Northridge ME, eds. The health of sexual minorities: public health perspectives on lesbian, gay, bisexual and transgender populations. New York, USA: Springer, 2007: 2-26.

64. Eisenberg ME, Wechsler H. Social influences on substance-use behaviors of gay, lesbian, and bisexual college students: findings from a national study. Soc Sci Med 2003; 57:1913-23.

65. Remafedi G. Lesbian, gay, bisexual, and transgender youths: who smokes, and why? Nicotine Tob Res 2007;9(Suppl 1):S65-71.

66. Remafedi G, Carol H. Preventing tobacco use among lesbian, gay, bisexual, and transgender youths. Nicotine Tob Res 2005;7:249-56.

67. Smith EA, Offen N, Malone RE. Pictures worth a thousand words: noncommercia tobacco content in the lesbian, gay, and bisexual press. J Health Commun 2006;11:635-49.

68. Gruskin E, Byrne K, Kools $\mathrm{S}$, et al. Consequences of frequenting the lesbian bar. Women Health 2006:44:103-20.

69. Lombardi E, Silvestre AJ, Janosky JE, et al. Impact of early sexual debut on gay men's tobacco use. Nicotine Tob Res 2008;10:1591-5.
70. Trinkets and Trash: Cigarette Industry Surveillance. American Spirit: 'Freedom to Breathe' (originally published in The Advocate, 21 June 2005, and Newsweek, 4 July 2004). http://www.trinketsandtrash.org/tearsheet.asp? ItemNum $=210691$ (accessed 25 March 2009).

71. Offen N, Smith EA, Malone RE. From adversary to target market: the ACT-UP boycott of Philip Morris. Tob Control 2003;12:203-7.

72. Smith EA, Malone RE. The outing of Philip Morris: advertising tobacco to gay men Am J Public Health 2003;93:988-93.

73. Smith EA, Offen N, Malone RE. What makes an ad a cigarette ad? Commercial tobacco imagery in the lesbian, gay, and bisexual press. J Epidemiol Comm Health 2005; 59:1086-91.

74. Stevens $\mathbf{P}$, Carlson LM, Hinman JM. An analysis of tobacco industry marketing to lesbian, gay, bisexual, and transgender (LGBT) populations: strategies for mainstream tobacco control and prevention. Health Promot Pract 2004;5(Suppl):S129-34.

75. Washington HA. Burning Love: big tobacco takes aim at LGBT youths. Am J Public Health 2002;92:1086-95.

76. Yamey G. Gay tobacco ads come out of the closet. BMJ 2003;327:296.

77. Montagu A. Man's most dangerous myth: the fallacy of race. 6th edn. Walnut Creek, California, USA: AltaMira Press, 1997.

78. Centers for Disease Control and Prevention (CDC). Racial/ethnic differences among youths in cigarette smoking and susceptibility to start smoking-United States, 2002-2004. MMWR Morb Mortal Wkly Rep 2006;55:1275-7.

79. Hahm HC, Wong FY, Huang ZJ, et al. Substance use among Asian Americans and Pacific Islanders sexual minority adolescents: findings from the National Longitudinal Study of Adolescent Health. J Adolesc Health 2008;42:275-83.

80. Ranney LM, Melvin CL, Lux L, et al. Tobacco use prevention, cessation, and control. Evidence report/technology assessment; no 140. Rockville, Maryland, USA.: Agency for Healthcare Research and Quality, 2006.

81. Sell RL. Defining and measuring sexual orientation: a review. Arch Sex Behav 1997:26:643-58.

82. Sell RL, Petrulio C. Sampling homosexuals, bisexuals, gays, and lesbians for public health research: a review of the literature from 1990 to 1992. J Homosex 1996;30:31-47.

83. Shively MG, Jones C, De Cecco JP. Research on sexual orientation: definitions and methods. J Homosex 1983:9:127-36.

84. Gruskin EP, Greenwood GL, Matevia M, et al. Cigar and smokeless tobacco use in the lesbian, gay, and bisexual population. Nicotine Tob Res 2007:9:937-40.

85. Pawelski JG, Perrin EC, Foy JM, et al. The effects of marriage, civil union, and domestic partnership laws on the health and well-being of children. Pediatrics 2006;118:349-64.

86. McManus AJ, Hunter LP, Renn H. Lesbian experiences and needs during childbirth: guidance for health care providers. J Obstet Gynecol Neonatal Nurs 2006:35:13-23.

87. Morrison LL, L'Heureux J. Suicide and gay/lesbian/bisexual youth: implications for clinicians. J Adolesc 2001;24:39-49.

88. Hooker E. The adjustment of the male overt homosexual. J Proj Tech 1957;21:18-31.

89. Offen N, Smith EA, Malone RE. Is tobacco a gay issue? Interviews with leaders of the lesbian, gay, bisexual and transgender community. Cult Health Sex 2008;10:14357.

90. Smith EA, Thomson K, Offen N, et al. "If you know you exist, it's just marketing poison": meanings of tobacco industry targeting in the lesbian, gay, bisexual, and transgender community. Am J Public Health 2008;98:996-1003.

91. Doolan DM, Froelicher ES. Efficacy of smoking cessation intervention among special populations: review of the literature from 2000 to 2005. Nurs Res 2006;55(Suppl):S29-37

\section{Search strategy}

Search terms covered sexual minority status (homosexuality OR homosexual OR gay OR "sexual minority" OR "female homosexuality" OR "homosexuality, female" OR lesbian OR bisexuality OR bisexual OR transgender OR transsexual OR transsexualism OR transsexuality OR MSM OR queer OR "sexual orientation" OR "men who have sex with men" OR WSW OR "women loving women" OR "women who have sex with women" OR lesbianism) and tobacco use (tobacco OR smoking OR smoker OR smokeless $\mathrm{OR}$ lobeline $\mathrm{OR}$ cotinine $\mathrm{OR}$ cigarette $\mathrm{OR}$ cigar $\mathrm{OR}$ habits $\mathrm{OR}$ habit $\mathrm{OR}$ "addictive behavior" OR addiction OR nicotine OR prevalence OR epidemiology). Truncations were not used because of incompatibilities with some databases. Searching was conducted from 26 to 27 May, 2007 